\title{
Do cognitive biases condition environmental concern? The case of Italy and Spain
}

\author{
Elisabetta Mannoni ${ }^{1}$
}

Recibido: 15/12/2020 / Aceptado: 3/03/2021

Abstract. This paper tackles whether it is possible to identify cognitive biases that foster environmental concern among public opinion. In particular, the study focuses on the mere exposure effect. Regression analysis was conducted on data concerning Spain and Italy to test the hypotheses that (1) exposing individuals to proenvironmental stimuli in the form of physical natural environments or recycling policies and (2) belonging to younger generations today is associated with a greater extent of environmental concern. The results confirmed both the hypotheses, suggesting environmental policies that affect individuals in their everyday lives, besides being beneficial for the environment, make the public opinion more conscious about the issue.

Keywords: environmental concern; cognitive biases; environmental policies; Spain; Italy

\section{[es] ¿Pueden los sesgos cognitivos condicionar la preocupación ambiental? El caso de Italia y España}

Resumen. El presente estudio busca investigar si los sesgos cognitivos - en particular, el de la mera exposición - puedan promover preocupación ambiental entre la opinión pública. Se llevó a cabo un análisis de regresión a partir de datos concernientes España e Italia para averiguar si (1) la exposición de individuos a estímulos proambientales en forma de ambientes físicos naturales o políticas públicas de reciclaje y (2) el pertenecer a las nuevas generaciones hodiernas estuvieran asociados a una mayor preocupación ambiental. Los resultados confirman ambas hipótesis y sugieren que las políticas ambientales que implican cambios en la vida diaria de los individuos, más allá de ser benéficas para el ambiente, concientizan a la opinión pública sobre el tema ambiental.

Palabras clave: preocupación ambiental; sesgos cognitivos; políticas ambientales; España; Italia

Index. 1. Introduction. 2. Theoretical framework. 2.1. Biases that may hinder or foster environmental concern. 2.2. Socio-demographic predictors of environmental concern. 2.3. Research question and hypotheses. 3. Data and methodology. 3.1. Data. 3.2. Measurement. 4. Results. 4.1. Exposure to proenvironmental stimuli. 4.2. Regression results. 5. Discussion. 6. Conclusions. Bibliography.

Cómo citar: Mannoni, E. (2021): Do cognitive biases condition environmental concern? The case of Italy and Spain, en Cuadernos de Gobierno y Administración Pública 8-1, 1-14.

\section{Introduction}

The climate emergency represents the most crucial crisis humankind has ever had to face. Such a life-threatening situation calls for urgent and consistent action of mitigation by governments and supranational institutions yet, such a concrete action has not been following (Funk et al., 2018). This inaction is precisely what lies at the heart of the question this analysis stems from. Why are substantial environmental policies not following? What kind of input is public opinion submitting to the political system? How concerned is it with climate change, and what psychological factors may affect this concern?
According to Easton's model of the political system (1957), the outputs produced by representatives in the form of policies are the product of a process in which, among other things, the inputs play a relevant role; inputs that citizens enter into the system, with their demands and requests of any kind. Furthermore, inputs also receive feedback from the system's output, inevitably linking all components of this cycle. Based on this theoretical framework, public opinion's environmental concern becomes key for a twofold reason. On the one hand, environmental policies or initiatives are unlikely to succeed if they cannot count on the citizenry's substantial support for their proper implementation. 
On the other hand, given that these policies are likely to be aimed at having citizens adopt an overall more sustainable lifestyle, it is crucial to know where the public opinion stands to have an idea of whether citizens may have a predisposition to also back those policies through individual voluntary actions, in their everyday activities and personal conduct.

All these things considered, this research aims at looking at the case of two Southern European countries, Spain and Italy, whose public opinion is usually labeled as less environmentally concerned compared to other European countries, investigate the extent of environmental concern of these populations, and identify those elements that sustainability strategies elaborated in these two countries shall account for. That is mainly done by looking at the climate crisis from a socio-psychological perspective, assuming that, in the words of the behavioral scientist Daniel Kahneman "to mobilize people, this has to become an emotional issue" (Marshall, 2016: 57). Thus, the analysis investigates whether it is possible to identify cognitive biases that can play a card in protecting the environment and fostering public opinion's environmental concern.

On this ground, and building on behavioral science theories, some expectations will be outlined on the effect of being exposed to certain environment-related stimuli and accounting for the recent increase in salience for the climate issue, especially relevant among younger generations. Regression analysis revealed that individuals living in Italian Regions or Spanish Autonomous Communities with stricter recycling policies and a higher proportion of natural spaces also showed a higher degree of environmental concern. Furthermore, belonging to the youngest generations, having a high level of education, as well as a high level of income, and being a woman rather than a man, emerged as good predictors of a higher degree of environmental concern, suggesting remarkable (and perhaps novel) elements to be taken into account when thinking about new policies aimed at fostering sustainability.

The remainder of the article is structured as follows: a first section will review the relevant literature on the topic and eventually outline the research question, the general expectation, and the particular hypotheses of this research. Secondly, information on the data used will follow, together with the operationalization and measurement of variables and the methodology. Then, the results of the regression analyses will be reported and duly commented, and followed by a section of concluding remarks that will um up the main elements of this research, relate the results to the original expectation of the analysis, outline its limits, and suggest interesting potential avenues for further research.

\section{Theoretical framework}

\subsection{Biases that may hinder or foster environmental concern}

It is common for citizens to lack substantial knowledge of political issues (Delli Carpini \& Keeter, 1991). How- ever, the lack of knowledge does not deter people from expressing a preference by casting a vote or giving an opinion on a specific issue. According to the literature on behavioral psychology, human brains would mostly opt for cost-effective ways of making decisions, relying on heuristics (i.e., cognitive shortcuts that bias our judgment). These allow them to exit the impasse situation of indecision they often face and make a choice that does not require too much effort and yet guarantees them a feeling of overall satisfaction (Kahneman, 2011). Sometimes we use heuristics even to take highly relevant decisions, both personally and socially - those decisions that, given their importance, we would expect to be the result of a rational analysis of costs and benefits. However, this is often not the case. Instead, in political and economic decisions, among many others, our choices are very much prone to distortion (Sniderman et al., 1991).

By means of experiments, Tversky and Kahneman (1974) found out a large number of individuals' choices are biased; that is to say, they are the final result of intuitive processes which at times might lead to a better choice, at times to a worse one, in terms of maximization of utility. What is remarkable is that this kind of decision-making process leads us to the most satisfactory choice for us at that moment, even if in terms of utility it is not the best one (Baldassarri, 2005). Therefore, our rationality does not consist of optimizing the result of choosing something based on consistency and coherence, but instead having the ability to "Take the Best; ignore the Rest" (Baldassarri, 2005: 55) - namely, identify the relevant cues and ignore the superfluous ones. Thus, we are not just randomly biased by the cues we select we systematically unconsciously follow some patterns that make things easier for us in terms of mental effort, depending on what we can recall, what we remember, what we saw, and what we think we saw.

Among the valuable cues at work regarding the environmental issue and the urgency needed to fight against global warming, some cognitive biases are instrumental in explaining why an equally unprecedented global action does not follow such an unprecedented global risk. Human brains are somehow "wired to ignore climate change" (Marshall, 2015: 226). The list of cognitive mechanisms that may potentially bias our judgment in favor of a lax attitude toward the issue of global warming is unluckily a long one. However, some of these cognitive shortcuts revolve around the same concept and can somehow be grouped and intended as a network of biases somehow connected to the other rather than isolated mechanisms working separately in human minds.

First, individuals' attitudes and behavior are time-sensitive. The end of history illusion has been identified as individuals' tendency to look at the present as the ultimate stage of their evolution as persons, and punctually underestimate the degree of change the future is likely to bring to them over time - "history, it seems, is always ending today" (Quoidbach et al., 2013: 98). If something happens to be unimaginable to us, we will also consider it unlikely to occur. Conceiv- 
ably, the end of history effect and the miscalculation it entails might contribute to the lack of action against the environmental crises, given that its consequences, despite the massive amount of information available and rationally knowledgeable on the topic, are for many privileged people still perceived as far from their present condition. On an analogous time-related line of reasoning, literature on hyperbolic discounting shows that extensive future damages have often almost no effect on individuals' present decisions, as is the case with fighting global warming (Karp, 2005). When thinking about trading off costs and benefits in a time dimension that is not the present, people tend to place less weight on the future moment than they do on the present one, acting as if the payoffs in the future were going to be lower ('discounted') than they are in reality.

Secondly, individuals' attitudes and behavior are biased against negativity and in favor of optimistic scenarios. The optimism bias leads individuals to be more inclined to believe in a more favorable outcome than negative ones (Hatfield \& Job, 2001). Wishful thinking prompt a tendency to predict better outcomes for one's favored 'team', be it their narrow social group, a broader community of theirs, or even their whole population (Babad \& Katz, 1991). Under the so-called ostrich effect, people ignore unfavorable events, even when it is undeniable that they are occurring or will occur (Karlsson et al., 2009).

Finally, the normalcy bias makes people in times of crisis initially underestimate the problem, hence interpret the situation as less disastrous than it is and be reluctant to solve it (Kuligowski \& Gwynne, 2010). The normalcy bias often takes the form of common statements like "it cannot happen to us" or "life will be unchanged even after a disaster" (Valentine \& Smith, 2002: 186), and a likely consequence of this bias is the incapacity of authorities to manage disaster or to involve civil society to participate to its management (Omer \& Alon, 1994). Consistently with this attachment to what is considered to be 'normal' and to the present moment, the status quo bias fosters a tendency to prefer well-known options to unknown alternatives. (Fernandez \& Rodrik, 1991).

All of this fits into the so-called System Justification Theory (SJT), according to which individuals find personal reassurance in the perception of a predictable system since it gives them the chance to feel like they can control it. Once they perceive the world as predictable, they can assume they live in a just society, justify its structures, legitimize its hierarchies (Jost \& Andrews, 2011). The SJT helps understanding the individual intertia in front of the crisis - justifying the existing system means embracing its way of functioning on the one hand by being supportive of it, as well as protecting its integrity, on the other hand, by rejecting threats to the status quo. Environmental policies by definition constitute a challenge to the status quo. Hence, the individual temptation dismiss these policies in defense of something they conceive as fair: the system as it is right now (Feygina et al., 2010). Indeed, research has revealed an inverse correlation between proenvironmental attitudes and factors typical of system justification, such as rightwing authoritarianism, conservatism, and social dominance orientation, all negatively associated with positive attitudes or behaviors toward the defense of the environment (Allen et al., 2007; Kilbourne et al., 2002; Sabbagh, 2005; Son Hing et al., 2007).

Unfortunately, the list of cognitive biases that foster environmental concern rather than hinder it is not as long. The availability heuristic, under which "people use salient instances of an event to judge its likelihood" (Deryugina, 2013: 5), has been reported to make people likely to think that climate change is real if they have personally experienced local fluctuations in temperatures, especially if recently (Deryugina, 2013). Egan and Mullin (2012) similarly showed people who had first-hand experienced a remarkable increase in temperatures tended to become more aware of the existence of the phenomenon of global warming. Kitschelt (1993) noted how even the nuclear catastrophe of Chernobyl in 1986 had increased the environmental concern among the public, while Hartwig and Tkach-Kawasaki (2020) found out the accident of Fukushima in 2011 positively affected Germans environmental concern. So, it is legit to conclude that recalling a recent calamity may foster individual environmental concern. Nevertheless, it would be non-sense to even think of building any reasonable safe strategy to foster environmental concern as dependent on the occurrence of catastrophes.

Another cognitive bias that could potentially play a role in favor of the defense of the environment is the mere exposure effect: the mere act of encountering something makes individuals inevitably familiar with it, and that familiarity, in turn, translates into a more positive attitude toward it than the one people had before they encountered that stimulus (Zajonc, 1968). Social experiments have revealed that the post-exposure positive attitude toward the stimulus is not generated by a conscious information process (Monahan et al., 2000). Instead, individuals can potentially be unaware of being exposed to any stimulus and still be affected by it (Zajonc, 2001) - no wonder this heuristic is massively employed in theories of marketing strategy and brand elaboration for the construction of advertisements (Kent \& Allen, 1994).

Consistently with this, as illustrated by Dunlap and Heffernan (1975), individuals who experience direct contact with nature tend to be more likely to appreciate the natural surroundings; hence, they suggested, this is likely to influence inclination to preserve the environment and nature in general. Therefore, it is reasonable to expect that people exposed more to natural or environmental stimuli tend to be more willing to worry about the environment and approve of environmental policies.

\subsection{Socio-demographic predictors of environmental concern}

For decades now, social scientists have been investigating the determinants of proenvironmental attitudes and 
behaviors. The most widespread theory on this is probably the cleavage between materialism and post-materialism, elaborated by Inglehart (1981). According to this theory, environmental concern only arises when individuals are in safe physical and economic conditions. However, widespread environmentalism in developing countries disproved the theory's validity, which would not be an acceptable explanation for the emergence of environmental attitudes, at least in the Southern hemisphere (Brechin \& Kempton 1994). However, despite not agreeing on post-materialism theory, scholars mostly agreed on the significance of at least two drivers toward concern about the climate issue.

First, gender was shown to be a strong determinant for concern about the environment, meaning women tend to be more sensitive to global warming than men and much more informed on the topic (McCright, 2010). An explanation for this was offered by Brough et al. (2016), who suggested that sensitiveness to the environmental issue was associated with femininity, which would make those men who are afraid of jeopardizing their masculinity less willing to take environmental stands and engage in proenvironmental activities or debates. Furthermore, ecofeminist theory (Puleo, 2013) takes inspiration from the closeness between women and nature. It builds upon the idea that patriarchal capitalism was built and kept itself alive by subordinating women, colonizing 'foreign' people, taking their lands, and ultimately ruling over nature. According to ecofeminism, the fact that women tend to undertake action in defense of the environment to a much greater extent compared to men is a datum, whose explanation lies in the fact that the subordination of women and the exploitation of nature are nothing but two sides of the same coin - they follow the same unjust and arbitrary logic of patriarchal domination.

Second, education is also generally considered a relevant contributor to the rise of concern about the environment, as the most educated individuals tend to be the most sensitive to global warming (Kemmelmeier et al. 2002; Kvaløy et al. 2012).

Finally, one could reasonably expect age to be a significant predictor of sensitiveness to the issue today, given that younger generations grew up in a context where environmentalism was already a reality. With all probabilities, they also are destined to live longer on this planet and participate in more evident consequences of the environmental crisis. However, as Vázquez (2020) pointed out, the significance of age as a powerful predictor for environmental concern still has to be proved. Yet, one should not discard the chance that the past few years might turn into a critical turning point, dividing a time when age was not so significant to determine sensitiveness toward the climate issue, from a time where younger generations end up chairing the debate (Watts, 2019).

\subsection{Research question and hypotheses}

The ultimate goal of this research is to identify those psychological cues that, rather than explaining the relatively lower level of concern about the issue, might enhance sensitiveness to the condition and fate of the environment. Is there a way cognitive biases may be launching a rope to an otherwise doomed environmental concern, even in countries where the issue is less salient?

The general expectation that will be tested is that the more easily people can recall experiences, objects, policies, emotions that have something to do with protecting the environment, the more sensitive they will tend to be toward the issue. To be tested, this hypothesis translates into two more specific hypotheses. First, based on the literature on mere exposure heuristic, we expect people living in regions with a greater extent of protection of the environment to be more concerned about it themselves. Worded less narrowly,

H1. The more exposed citizens are to pro-environment stimuli, the more concerned they will be about the environment.

Second, considering the relevance of current times for the evolution and salience of the environmental debate, the second hypothesis is that young people are now more sensitive to climate change than those who were young (hence got politically socialized) in the past.

$\mathrm{H} 2$. Belonging to the youngest generations of today is a good predictor for a higher degree of environmental concern.

\section{Data and methodology}

\subsection{Data}

Both hypotheses will be tested employing regression analysis. Since this research focuses on environmental attitudes of the public opinion, data measuring environmental concern will be used from the last wave of the European Values Study (EVS), which includes surveys conducted both for Spain (2017) and Italy (2018) (EVS, 2020). Although EVS offers information on socio-demographic variables and attitudes towards the environment, it does not include data on variables measuring public opinion exposure to pro-environmental stimuli.

Thus, these data were collected on the one hand from country reports on the EU Natura 2000 network, detailing information on protected natural areas in each region of the country under the Bird directive and Habitat directive, retrievable on the official pages of Environmental Ministers of both countries (Ministero dell'Ambiente, 2020; MITECO, 2020). On the other hand, they were retrieved from national agencies (INE 2020; ISPRA, 2020), providing information on environmental policies enacted by national or local governments to measure citizens' exposure to positive stimuli toward the tendency to care for the environment..

\subsection{Measurement}

Environmental concern (DV). From 1990 to 2018, environmental concern was conceptualized quite differently 
from one EVS wave to another, leading to investigating this attitude in ways that varied over the years both in quantity and quality. The content difference did not lie only in the wording adopted but mainly in the relationship between human beings and the environment that the items would stress. In 2017 and 2018 - and for the first time compared to previous waves of EVS - the survey items included to investigate environmental concern posed attention to the existential dilemma the climate emergency implies. So this battery is particularly noteworthy compared to the previous ones, as it includes negatively worded sentences that highlight, for instance, the difficulty for a single individual to make the difference in ecological terms. They also address the frustration that derives from thinking that individual action is less effective than collective action, making individual action look pointless. Moreover, they also bring attention to the actual location of the environmental issue in individuals' hierarchy of priorities. Furthermore, the last wave includes an item ("I would give part of my income if I were certain that the money would be used to prevent environmental pollution") that is the only one present across all EVS waves measuring environmental concern since 1990.

For all of these reasons, factor analysis was conducted to build an internally consistent index for environmental concern. It included all the seven items - six statements the respondent could 'strongly agree', 'agree', 'neither agree nor disagree', 'disagree', or 'strongly disagree' with, and one item presented as a demarcation issue, offering the respondent the chance to choose between to two goals presented as mutually exclusive (see Table 1). This last item recalls the dichotomy economy-environment, intended as an equation where the defense of the second requires the sacrifice of the first. It goes beyond the purpose of this analysis to debate on the potential shortfalls of a conceptualization that excludes a priori the whole range of avenues of sustainable development, where economic development and protection of the environment, rather than being one the enemy of the other, may instead benefit from each other. Here, it will suffice to say that it appeared to be consistent with the other four new items when included in the index and was therefore kept.
The first attempt to build an index that included all the seven items contained in the questionnaire led to realizing that the first statement, asking the respondents whether they would be willing to donate part of their income to the fight against pollution, did not constitute a coherent element with the other items of the index. In fact, despite a relatively high Cronbach's alpha $(\alpha=$ $.69)$, its factor loading for Factor 1 (eigenvalue $=2.46$ ) was much lower than any other (see Table 6). Dropping it resulted in a more internally consistent index $(\alpha=.73)$.

Exposure to pro-environment stimuli (IV1). First, EVS datasets provide information on the dimension of the municipality of the respondent. Assuming that living in a more urban rather than a rural area does often imply the chance to be surrounded by more or less natural elements, this variable was coded in such a way to have three different categories differentiating respondents between those living in cities ( $>100,000$ inhabitants), those living in towns (20,000-100,000 inhabitants) and those living in villages or rural areas $(<20,000$ inhabitants $)$.

Secondly, starting from data from Natura 2000, the extent of exposure to natural stimuli was measured through two other variables, one showing the number of different protected sites present in the administrative region considered (Special Areas of Conservation, SACs), expressed as an absolute value; the other showing the proportion of protected areas over the whole regional territory (Sites of Communitarian Importance, SICs), expressed as a percentage. The first accounts for the variety of the natural stimuli across the region, whereas the second for their coverage.

Thirdly, in order to include in the analysis a pro-environment stimulus of political nature and test the effect of something which is not merely given, but instead ad hoc created by national or local governments, the portion of urban waste produced at the regional level that happens to be recycled was included in the analysis. The choice of using this as a valid proxy for pro-environment stimulus rather than other political measures aimed at sustainability lies in the fact that the demand for recycling has the absolute power to enter into citizens' houses more intrusively and frequently than, for instance, the creation of urban green areas or the implementation of bike-sharing.

Table 1. Factor 1 loadings for each of the six items on environmental concern for Spain and Italy 2017-18 (EVS, 2020).

\begin{tabular}{|l|c|}
\hline \multicolumn{1}{|c|}{ Statement } & Factor \\
\hline I would give part of my income if I were certain that the money would be used to & $.32 *$ \\
\hline prevent environmental pollution & .65 \\
\hline It is just too difficult for someone like me to do much about the environment & .75 \\
\hline There are more important things to do in life than protect the environment & .76 \\
\hline There is no point in doing what I can for the environment unless others do the same & .67 \\
\hline Many of the claims about environmental threats are exaggerated & .57 \\
\hline $\begin{array}{l}\text { Which statement comes closer to your own point of view? } \\
- \text { Protecting the environment should be given priority, even if it causes slower economic growth and some loss of jobs } \\
\text { - Economic growth and creating jobs should be the top priority, even if the environment suffers to some extent }\end{array}$ & .5 \\
\hline
\end{tabular}

Note. *Dropped item.

(Source: own elaboration). 
Generation (IV2). To test whether being socialized within a specific historical context makes the difference, a generation variable was computed and recoded in such a way so to differentiate observations between individuals belonging to different cohorts. The generation division here applied is the one generally used by the Pew Research Center (Dimock, 2019; Taylor et al., 2014). Hence, there will be the 'Seniors generation' (also known as 'Silent generation', born until 1945); 'Babyboomers' (1946-1964), 'Gen Xers' (1965-1980); 'Generation Y' or 'Millennials' (1981-1996), and 'Generation Z' (1997 to roughly 2012). Given the exiguous number of observations available for Generation $\mathrm{Z}$ and the youngest generations' relevance for this analysis, the regression analyses treat $\mathrm{Gen} Y$ and Gen $\mathrm{Z}$ as belonging to the same category.

Control variables. As for gender, the sample was divided into males and females. As for income, respondents were assigned to one of three income categories depending on whether they had a low (from the first to the third decile), medium (from the fourth to the sixth decile), or high (from the seventh to the tenth decile) income level. Similarly, they were assigned to a low, medium, or high level of education, depending on what age they had studied. Several operationalization attempts were made to account for the differences between the Spanish and the Italian education systems. Eventually, the dividing lines between one level and the other were set at 14 years old (to roughly separate those with a low level of education from those with a medium one) and at 19 years old (to approximately separate those with a medium level of education, who dropped school once they graduated from high school, from those who went to university, getting to a higher education level).

Finally, the respondents' regions were recoded to have both countries divided into three areas - North, center, and South. It shall be noticed that, while for Italy, these areas actually coincide with the geographic north, center, and south of the country, this was not the case for Spain. The rationale behind the codification of this variable consisted of getting an "economic north" and "economic south" to compare to an intermediate area of reference (the center). The "economic north" consists of the wealthiest regions, where the GDP per capita is generally higher, the unemployment rate lower, and there tends to be a much greater extent of industrialization. These regions are the Italian Piemonte, Liguria, Lombardy, Trentino-Alto Adige, Friuli-Venezia Giulia, Veneto, and Emilia-Romagna ; and the Spanish Catalonia, Bask Country, La Rioja, Navarra, and Madrid. Along the same line of reasoning, regions in the "economic South" are Campania, Abruzzo, Molise, Basilicata, Apulia, Calabria, Sicily and Sardinia for Italy, or Canary Islands, Andalucía, Murcia, Castilla-La Mancha and Extremadura for Spain. All remaining regions and autonomous communities belong to the center and are used as the regression results' reference category.

\section{Results}

\subsection{Exposure to proenvironmental stimuli}

Figures 1.1 and 1.2 show the geographic distribution of SICs, whereas Figures 2.1 and 2.2 report the total number of SACs identified in Italy and Spain under the European directive for each region and autonomous community. By comparing the two maps for each country, we notice that a higher number of SACs is not necessarily associated with a higher portion of protected SICs, as regions who score higher in one of the two indicators might score very low in the other, and vice versa. Overall, no pattern seems to correlate northern or southern regions to lower or greater extents of SICs and SACs.

On the other hand, figures 3.1 and 3.2 display the extent to which local administrations expose their citizens to a proenvironmental stimulus by having the region recycle

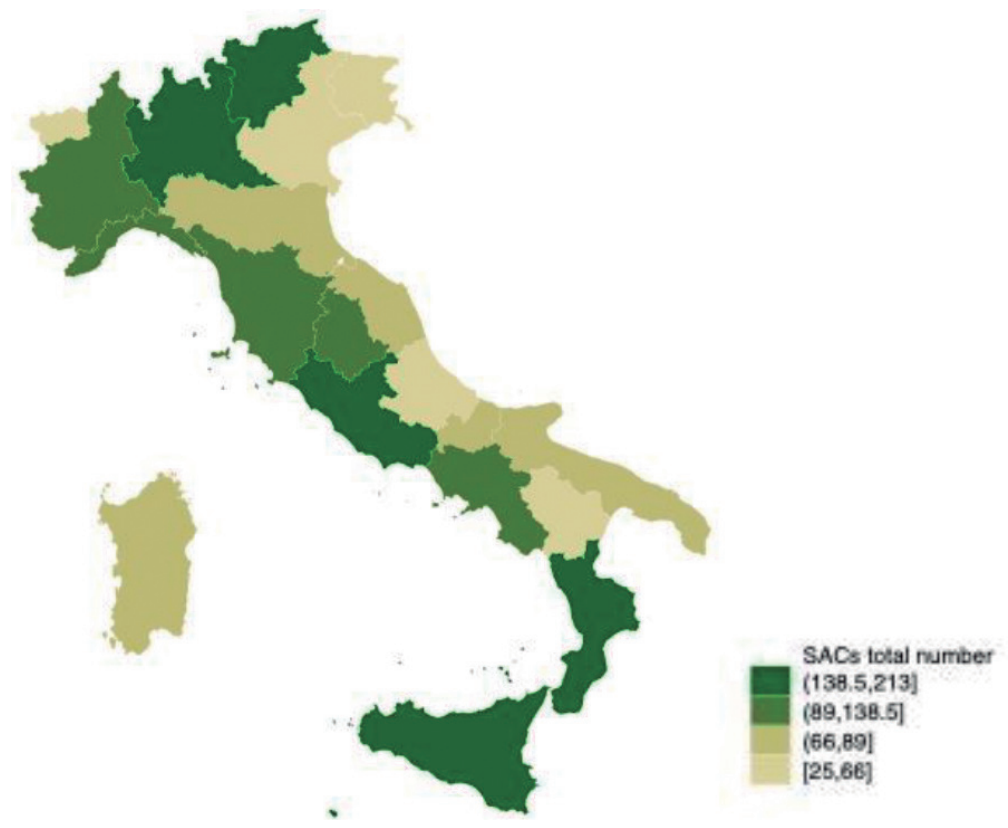

Figure 1.1. Percentage of protected territory identified as SICs (Source: own elaboration based on Ministero dell'Ambiente, 2020). 


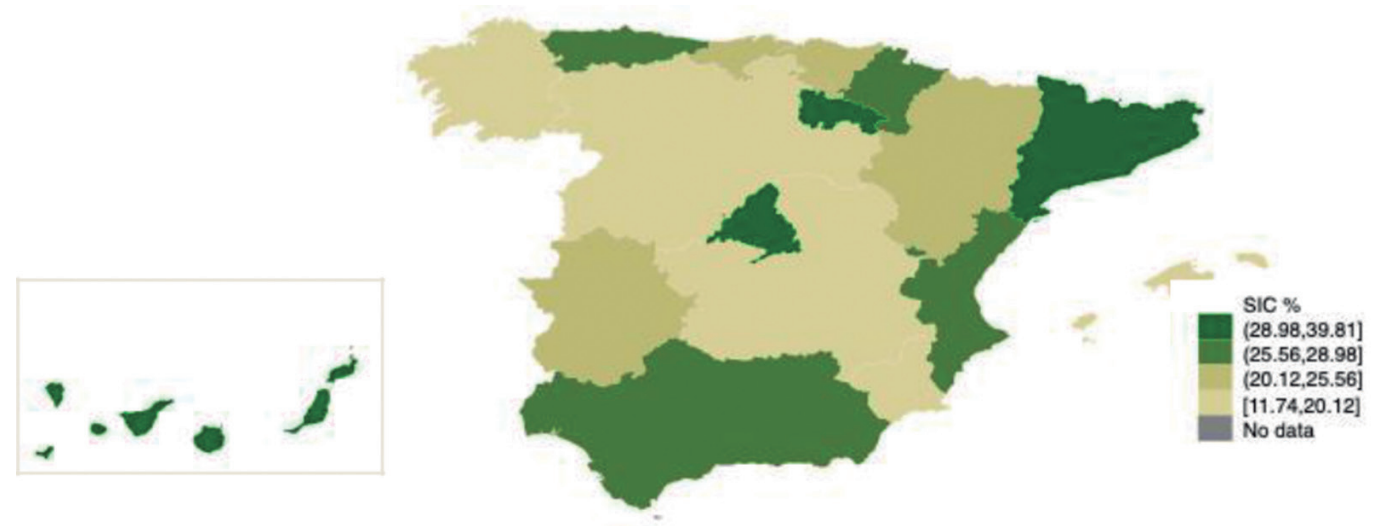

Figure 1.2. Percentage of protected territory identified as SICs (Source: own elaboration based on MITECO, 2020).

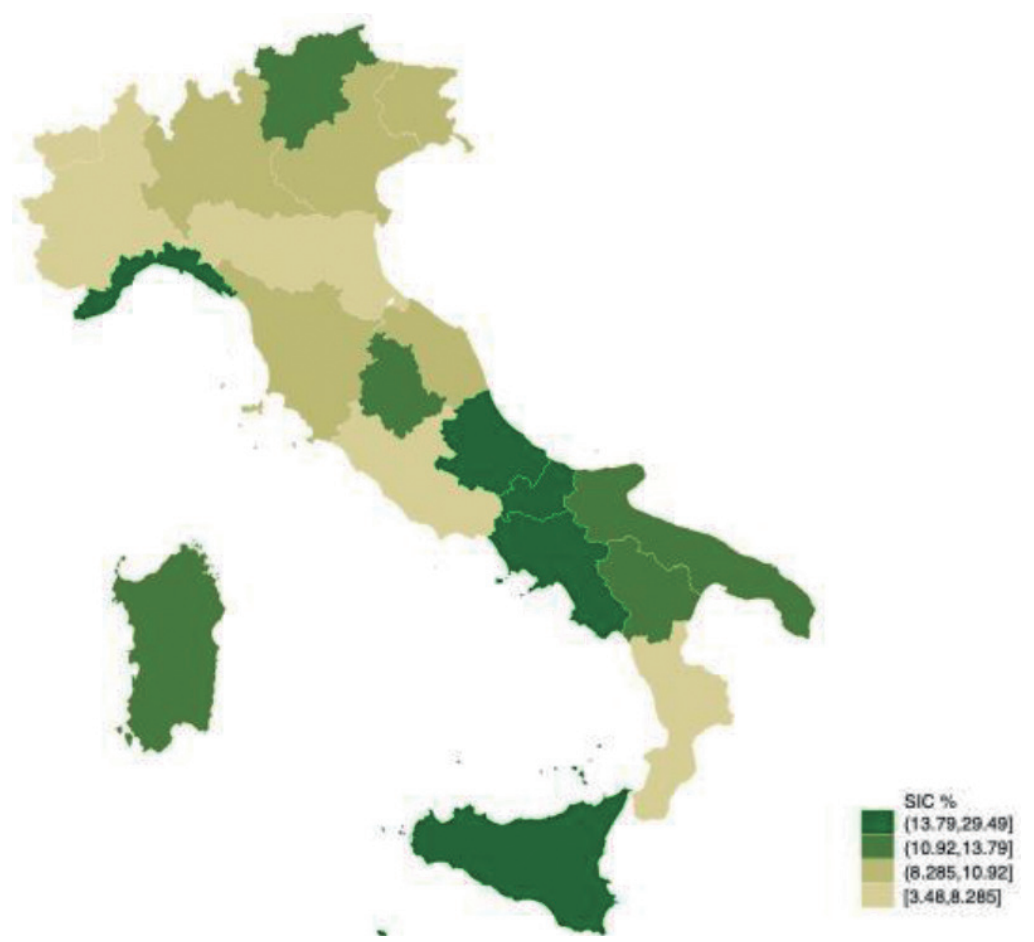

Figure 2.1. Number of SACs (Source: own elaboration based on Ministero dell'Ambiente, 2020).
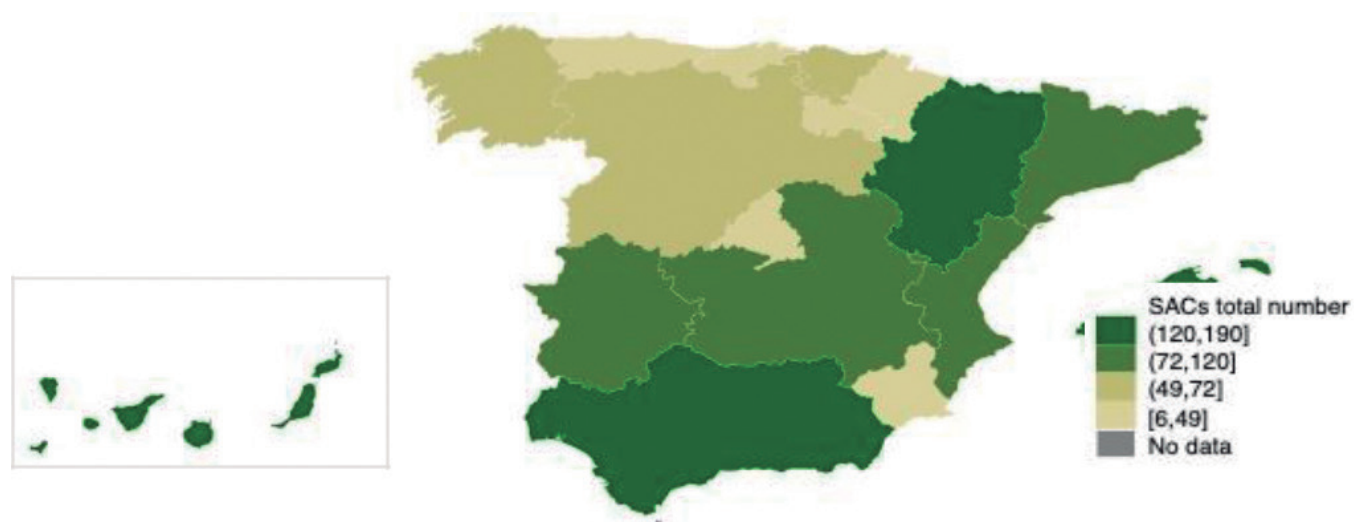

Figure 2.2. Number of SACs (Source: own elaboration based on MITECO, 2020) 


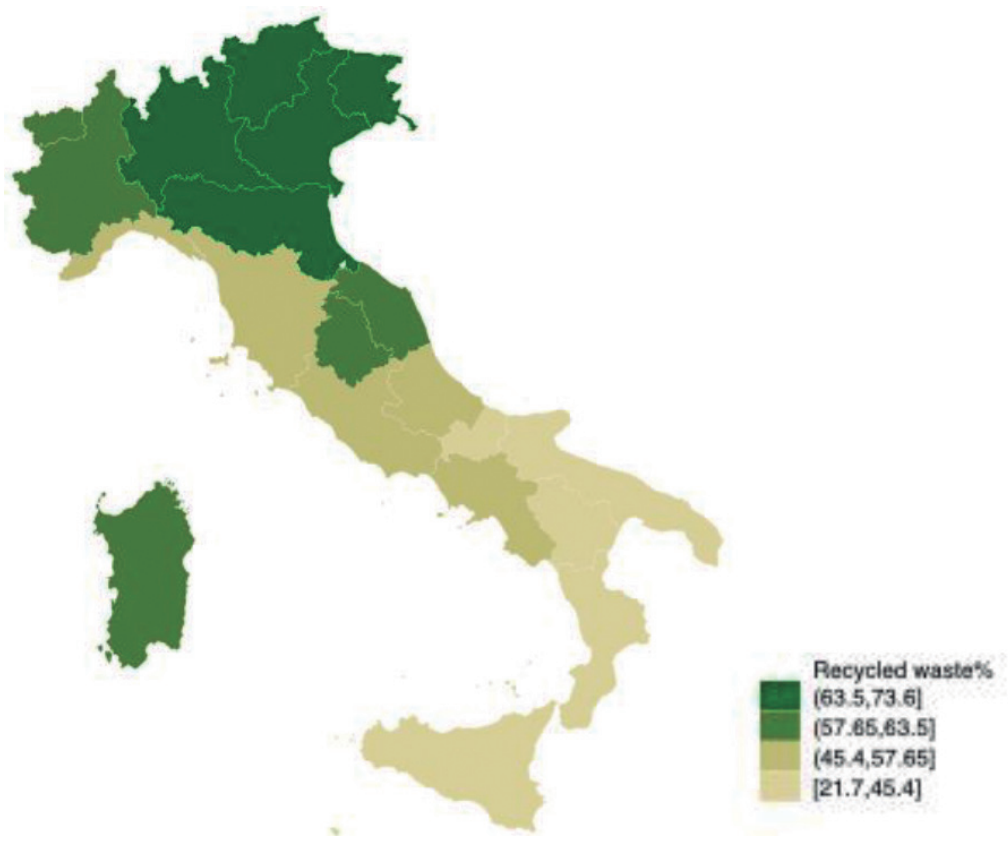

Figure 3.1. Percentage of recycled waste over total urban waste (Source: own elaboration based on ISPRA, 2020).
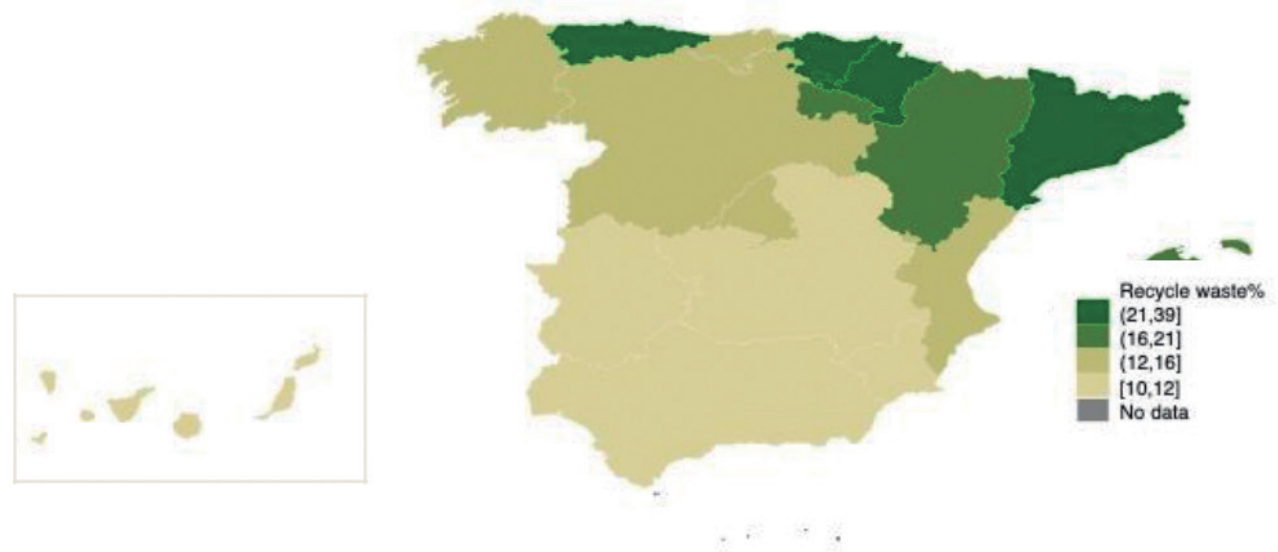

Figure 3.2. Percentage of recycled waste over total urban waste (Source: own elaboration based on INE, 2020).

a higher or lower percentage of the total urban waste produced. Whereas so far maps had not revealed any remarkable pattern, here things change, and it can immediately be noticed, both for Italy and Spain a difference between richer and poorer regions, the former registering higher percentages of recycled waste, the latter showing lower values - reaching 10\% in the case of Murcia in Spain.

Looking at the three different maps for each of the two countries helps clarifying a crucial aspect of this part of the investigation here conducted: identifying variables that can be valid proxies for exposure to pro-environment stimuli is not an easy task, and the chances are that none of the ones here chosen is a perfect candidate for the job. However, several intents to use them and test the first and main hypothesis of this analysis were done by including them in different regression models, controlling for each other and the type of municipality respondents lived in. Since these variables are indicators of quite different nature yet representing the same independent variable, the analysis showed below also accounts for the interaction of the two variables. Regression results are shown in Tables 2.1 and 2.4 for Italy and Spain together, Table 2.2 for Italy only, and Table 2.3 for Spain only.

\subsection{Regression results}

The first regression model (Tab. 2.1) reveals that among the potential variables considered as indicators of exposure to environmental stimuli, the only one that is significantly associated with a greater extent of a positive attitude toward the environment in Italy and Spain is that regarding the percentage of recycled waste in the respondent's region of origin. This variable is positively associated with the dependent variable - meaning that to a greater extent of recycling is associated a greater extent of environmental concern. One could argue that this might be because the regions with stricter environmental policies also tend to coincide with those where income and education levels are relatively high; this would be a 
legit intuition, but the model controls for those variables at the individual level, as it can be seen below, and therefore the effect of recycling policies here highlighted is a net effect. The other proxies included, namely, the number of SACs and the percentage of territory identified as SICs, do not present a significant association with the outcome variable, and neither does the type of surrounding the respondent lived in.

Being Spanish rather than Italian did not have a significant effect on environmental concern either, while it did have an effect - and a negative one - living in the wealthiest areas of the two countries (which also tend to be the most industrialized ones). As for the other variables, it is worth confirming the relevance of education as the variable with the highest (positive) effect on environmental concern, followed by income - both variables whose effects are widely documented in the literature. For income, belonging to the highest levels is what makes the difference in terms of environmental concern. Whereas when it comes to education, even having a medium level of education significantly affects the attitude toward the environment compared to having a low level of education; and yet going to university happens to have an even more substantial effect - indeed, it is the strongest predictor of environmental concern across the whole model. The regression also seems to confirm the theory on ecofeminism since it shows that being a woman has a significant effect on the attitude toward the natural environment. Finally, belonging to a younger generation is significantly associated with a more environmentalist inclination. All generations seem to be significantly more concerned about the environment than the Seniors, and belonging to Gen $\mathrm{X}, \mathrm{Y}$, or $\mathrm{Z}$ seems to have a more substantial impact than being a Babyboomer.

However, analyzing Spain and Italy together might hide some somewhat relevant pieces of information. When analyzing regression results for the two countries separately, interesting findings come out. First, the regression model for Italy (Tab. 2.2) shows that belonging to the country's Southern regions tends to affect environmental concern negatively. Regarding the exposure to proenvironmental stimuli in single-country regressions, considering what was said above concerning the distinct nature of the variables identified as indicators of such exposure, an independent variable was added to the model that somehow accounted for at least two of them. Namely, the interaction between the percentage of areas identified as worthy of protection under the Habitat directive and the percentage of urban waste that regions recycle. Such interaction resulted as having a significant, for slight, positive effect in enhancing environmental concern.

The significance of such interaction reveals a positive effect that living in regions with higher levels of waste recycling and larger extents of biodiversity has on being concerned about the well-being of the environment. For what concerns the other variables, living in a village rather than a town or a city does not seem

Table 2.2. Regression results for environmental concern in Italy in 2018 (EVS, 2020).

\begin{tabular}{|l|c|c|c|c|c|c|c|}
\hline Condition and control variables & $\boldsymbol{\beta}$ & $\boldsymbol{S E}$ & $\boldsymbol{p}$ & $\boldsymbol{F}$ & $\boldsymbol{d} \boldsymbol{f}$ & $\mathbf{R}^{2}$ & $\boldsymbol{n}$ \\
\hline Environmental concern in Italy & & & & 12.16 & 13,1415 & .10 & 1429 \\
\hline Generation & & & & & & & \\
\hline Babyboomers & $.34^{* * *}$ & 0.08 & .000 & & & & \\
\hline Gen X & $.40^{* * *}$ & 0.08 & .000 & & & & \\
\hline Gen Y+Z & $.43^{* * *}$ & 0.09 & .000 & & & & \\
\hline Female gender & .08 & 0.05 & .090 & & & & \\
\hline Income level & & & & & & & \\
\hline Medium & .10 & 0.06 & .100 & & & & \\
\hline High & $.21^{* *}$ & 0.07 & .004 & & & & \\
\hline Education level & & & & & & & \\
\hline Medium & $.26^{* * *}$ & 0.07 & .000 & & & & \\
\hline High & $.43^{* * *}$ & 0.08 & .000 & & & & \\
\hline Municipality & & & & & & & \\
\hline Town & -.02 & 0.07 & .795 & & & & \\
\hline Rural area & -.04 & 0.06 & .490 & & & & \\
\hline Pro-environment stimulus ${ }^{6}$ & $.00^{* *}$ & 0.00 & .009 & & & & \\
\hline Area & & & & & & \\
\hline North & -.04 & 0.07 & .615 & & & \\
\hline South & $-.22^{* *}$ & 0.08 & .005 & & & \\
\hline Constant & 0.11 & .000 & & & \\
\hline
\end{tabular}

${ }^{*} p<.05,{ }^{* * *} p<.01,{ }^{* * *} p<.001$

(Source: own elaboration). 
to have any significant effect. Moreover, contrary to the previous regression results, being a woman rather than a man does not significantly influence environmental concern in Italy. On the other side, we can confirm for Italy taken individually too, the relevance of having a higher school degree - the higher, the better. Indeed, despite being slightly less influencing than in the previous model, education is the most relevant variable in this and all models. Income is also relevant, as having a very high economic capacity seems to be a significant determinant of environmental concern.

Finally, and quite relevantly, given the questions this research aims at tackling, according to the regression results, belonging to a younger generation would indeed foster the tendency to be worried about the future of the planet. If in the previous model that also accounted for data from Spain, being a Gen Xers did not seem to be a worse predictor for environmental concern than being a Millennial or belonging to the Generation Z, this regression for Italy shows precisely that: being Millennial or from Gen $\mathrm{Z}$ is what makes the most significant difference.

The third regression model (Tab. 2.3), displaying the results for Spain in 2017, shows commonalities and notable differences compared to Italy's model. First and foremost, the interaction between the portion of protected naturalistic areas and the percentage of urban waste recycled, as noticed for Italian public opinion, happens to have a positive slight but significant effect on environmental concern. Income and education are confirmed to be positive indicators, like in the previous model. Even for Spain, when all these variables are present in the model, living in a small village instead of a big city does not have a significant relationship with the dependent variable. On all these aspects, then, Italian and Spanish public opinion seem to converge.

However, they do not converge on the role of gender and the area of the country where the respondents live. Gender, which did not seem to have any effect in Italy, has it in Spain, with a lower p-value and a higher coefficient than the well-rooted income. That itself is a finding worthy of a short discussion below. Other than that, the other remarkable difference lies in the association found between living in what we have called the "economic North" and living in the "economic South", compared to living in the center. Living in the wealthiest regions of Spain is very negatively associated with environmental concern; the opposite happens with living in the poorest ones, where the association found is a positive one, although not as strong as the one found for the north. We saw that for Italy, belonging to the Northern regions did not imply any effect while belonging to the Southern ones had a negative one. Finally, a variable that we had found to be an indicator of proenvironmental attitude in Italy - generation - was not a good predictor at all for environmental concern in Spain. We will elaborate on this and other discrepancies between Spanish and Italian public opinion when discussing these findings in the next section.

Table 2.3. Regression results for environmental concern in Spain in 2017 (EVS, 2020).

\begin{tabular}{|l|c|c|c|c|c|c|c|}
\hline Condition and control variables & $\mathbf{B}$ & $\boldsymbol{S E}$ & $\boldsymbol{p}$ & $\boldsymbol{F}$ & $\boldsymbol{d} \boldsymbol{f}$ & $\mathbf{R}^{2}$ & $\boldsymbol{n}$ \\
\hline Environmental concern in Spain & & & & 7.46 & 13,716 & .12 & 730 \\
\hline Generation & & & & & & & \\
\hline Babyboomers & .13 & 0.07 & .320 & & & & \\
\hline Gen X & .21 & 0.07 & .118 & & & & \\
\hline Gen Y+Z & .15 & 0.08 & .310 & & & & \\
\hline Female gender & $.22^{* *}$ & 0.07 & .003 & & & & \\
\hline Income level & & & & & & & \\
\hline Medium & .11 & 0.09 & .222 & & & & \\
\hline High & $.27^{* *}$ & 0.10 & .007 & & & & \\
\hline Education level & & & & & & & \\
\hline Medium & $.28^{* *}$ & 0.10 & .005 & & & & \\
\hline High & $.55^{* * *}$ & 0.11 & .000 & & & & \\
\hline Municipality & & & & & & & \\
\hline Town & -.02 & 0.10 & .863 & & & & \\
\hline Rural area & -.16 & 0.09 & .075 & & & & \\
\hline Pro-environment stimulus & .00 & 0.00 & .003 & & & & \\
\hline Area & & & & & & \\
\hline North & $-.57^{* * *}$ & 0.16 & .000 & & & & \\
\hline South & -.92 & 0.17 & .000 & & & & \\
\hline Constant & & & & & \\
\hline
\end{tabular}

${ }^{*} p<.05,{ }^{* *} p<.01,{ }^{* * *} p<.001$

(Source: own elaboration). 
Finally, the last model (Table 2.4) accounts for the conditional effect of an interaction between the context and the individual level. In particular, the interaction between a variable indicating the overall pro-environment stimulus and the generation variable. The only generation category for which a significant effect is found is precisely the youngest one (i.e., Millennials and Generation Z). Hence, we can conclude that only for that generation being exposed to a greater extent of environmental stimuli is a good predictor of a higher level of environmental concern than the Silent generation's.

Besides that, this last regression also confirms all the other statistically significant predictors that had already been identified as such according to the previous regression models: medium and high levels of education, with the latter, almost doubling the effect of the former; high and medium level of income, although the latter to a much lesser extent; and gender. Finally, living in Spain seems not to be a good incentive toward being worried about the environment.

\section{Discussion}

The results show that being embedded into a context that sends pro-environment inputs, both naturally and politically, enhances environmental concern. That possibly finds confirmation in the illuminating finding that in Spain, living in the most developed and industrialized regions constitutes a predictor for a lower environmental concern, whereas living in the poorest regions is associated with a greater extent of care about the future of the planet. That is of particular interest also in light of what was said on the theory of post-materialism, since data here would seem to go less in the direction of that theory and more toward the ones that criticized it, highlighting the very materialistic nature of the climate issue itself, whose consequences tend to be paid by the poorest social groups.

Furthermore, the idea that getting socialized to politics nowadays, rather than earlier, might make the difference in terms of environmental concern found solid

Table 2.4. Regression results for environmental concern in Italy and Spain in 2017-18 (EVS, 2020).

\begin{tabular}{|l|c|c|c|c|c|c|c|}
\hline \multicolumn{1}{|c|}{ Condition and control variables } & $\boldsymbol{B}$ & $\boldsymbol{S E}$ & $\boldsymbol{p}$ & $\boldsymbol{F}$ & $\boldsymbol{d} \boldsymbol{f}$ & $\mathbf{R}^{2}$ & $\boldsymbol{n}$ \\
\hline Environmental concern in Italy and Spain & & & & 12.36 & 17,2141 & .09 & 2159 \\
\hline Female gender & $.13^{* *}$ & 0.04 & .002 & & & & \\
\hline Income level & & & & & & & \\
\hline Medium & $.10^{*}$ & 0.05 & .040 & & & & \\
\hline High & $.22^{* * *}$ & 0.06 & .000 & & & & \\
\hline Education level & & & & & & & \\
\hline Medium & $.26^{* * *}$ & 0.06 & .000 & & & & \\
\hline High & $.48^{* * *}$ & 0.06 & .000 & & & & \\
\hline Municipality & & & & & & & \\
\hline Town & .01 & 0.06 & .889 & & & & \\
\hline Rural area & -.03 & 0.05 & .611 & & & & \\
\hline Generation & & & & & & & \\
\hline Babyboomers & .12 & 0.14 & .384 & & & & \\
\hline Gen X & $.30^{*}$ & 0.14 & .035 & & & & \\
\hline Gen Y+Z & .06 & 0.15 & .698 & & & & \\
\hline Pro-environment stimulus & -.00 & 0.00 & .397 & & & & \\
\hline Pro-environment stimulus X & & & & & & & \\
\hline Generation & & & & & & & \\
\hline Babyboomers & .00 & 0.00 & .266 & & & & \\
\hline Gen X & .00 & 0.00 & .811 & & & & \\
\hline Gen Y+Z & $.00^{*}$ & 0.00 & .041 & & & & \\
\hline Area & & & & & & & \\
\hline North & -.04 & 0.06 & .505 & & & & \\
\hline South & -.03 & 0.06 & .666 & & & & \\
\hline Country & & & & & & & \\
\hline Spain & $-.10^{*}$ & 0.04 & .031 & & & & \\
\hline Constant & 0.14 & .000 & & & & \\
\hline$<05$ & & & & \\
\hline
\end{tabular}

$p<0.05,{ }^{* *} p<0.01,{ }^{* * *} p<0.001$

(Source: own elaboration) 
ground for Italy's case, but it did not for Spain's case. Here a clarification is due: the EVS survey was conducted in Spain between November 2017 and January 2018, while for Italy, the investigation took place afterwards, between September 2018 and January 2019. The FridaysForFuture movement was launched by the young activist Greta Thunberg in August 2018. Far from claiming this was a natural experiment, given that the difference between the two countries might be due to their different histories and plenty of other reasons, these findings give ground to affirm that Spain's case shall be investigated with more recent data. It would make for an interesting case to see whether the exposure to the environmentalist movement born in 2018 did make a difference among the younger Spanish generations.

Beyond the results strictly related to this research's hypotheses, the analysis suggested other relevant insights worthy of highlighting. First, Spanish public opinion seems to be overall less environmentally concerned than Italian public opinion. The highest percentages of recycled urban waste reached in Spain was almost 40\% registered by the Bask Country and Navarra, whereas in Italy only Calabria, Molise and Sicily presented a percentage lower than $40 \%$. In comparison, the other 17 regions get to recycle up to more than $70 \%$, as is the case for Veneto or Trentino Alto Adige - this can be good news, as it may indicate that Spanish autonomous communities can improve their recycling policies and, in turn, enhance environmental concern among their citizens.

Furthermore, the strong effect education has on environmental concern was confirmed, and the highest level of education is, by all means, the most effective one. The more people go to school or university, the more concerned they become about climate change. This means education shall never be excluded from elaborating sustainability strategies, since the first strategy (given the strength of this variable's effect as revealed by the models) passes precisely through schools and universities. Guaranteeing the right to study and to get educated to all layers of the society and all social classes by keeping education affordable is crucial, and both Italy and Spain offer avenues in this sense, although Covid-19 has brought to the field new challenges and patterns of inequalities that need to be urgently addressed.

Moreover, rates of young unemployment are still relatively high in both countries, and plenty of young people would instead learn a profession and go to work once high school is over, rather than spend several years studying only to end up holding a diploma that will guarantee access to unpaid internships. That might discourage many young people who have to decide whether to keep studying or not. Fixing this problem might incentivize the willingness to keep studying and the formation of more aware citizens. On the other hand, considering that people can genuinely not be interested in going to university, covering environmental issues and climate change in a significant manner from the first year of school, substantially including it in all programs, becomes crucial.

Also, having a medium, but especially a high-income level is positively correlated with environmen- tal concern. While it is impossible to move the whole population to the highest deciles of income, it is also true that decreasing economic inequalities by lifting the most disadvantaged categories is a goals. That holds especially true if we think of existential nature of the environmental concern. To measure it, people are asked to what extent they agree with statements such as "It is too difficult for someone like me to do much about the environment" or "There is no point in doing what I can for the environment unless others do the same". That is what the willingness to stand for the environment requires - believing every single one can make something, that big changes start small, and there is a point in doing what one does. Yet, it is not so hard to imagine how economically disadvantaged people, that already feel marginalized in several other contexts and occasions, grow up to the idea that their contribution is pointless and their capabilities way too limited. Similarly, in a society where money and power are synonyms, and almost everything can be bought, no wonder the wealthiest layers of society are filled with people who grow up knowing that they just can - it does not matter what other words fill this sentence. Lifting disadvantaged people, besides being imperative to a fair democracy, is key to a sustainable one.

Last but not least, gender seems to be relevant too. In line with ecofeminism, being a woman rather than a man predicts a greater extent of environmental concern - although this effect was absent when Italy was examined separately, and this difference with Spain is worthy of further investigation. So, once again, this can give relevant insights to those willing to bring change: it compels a deconstruction of what was defined as toxic masculinity, according to which caring is a prerogative of women, associated with the dichotomy nature/emotions, while men are identified with culture/rationality. This deconstruction, again, passes through policies - e.g., allowing a fair division of domestic care activities and the gender balancing both in areas generally populated almost exclusively by men and those populated almost exclusively by women. Eventually, even male chauvinism turns out to be an enemy of sustainability, and one sustainable societies are urged to fight.

\section{Conclusions}

This research stemmed, before anything else, from the global emergency that the climate crisis represents nowadays. It is not only the biggest crisis humankind has ever had to face, but also the biggest one it has generated and whose worsening it keeps perpetuating daily through a way too unsustainable lifestyle of the global north, which does not get to be mitigated despite the below-average standard of living of most countries in the global south. Whereby is the question, What kind of inputs is public opinion inserting into the political system if the result is scarce? If the input is not a sufficiently demanding and assertive one, how can a change in the output incentivize an improvement in the input, 
further improving the output, in a cycle only destined to turn into more sustainable policies gradually? How can environmental concern of public opinion be fostered so that they demand more sustainable policies, which in turn would possibly promote environmental concern?

Building on the theory on heuristics and biases, this analysis aimed at testing the expectation that, despite being cognitive biases one of the reasons why people tend not to prioritize enough the climate issue compared to other issues, they might also work the other way around, that is to say, to foster environmental concern. In particular, regression analysis was conducted on Spain and Italy's data to test the hypotheses that (1) exposing individuals to proenvironmental stimuli in the form of physical natural environments or recycling policies and (2) belonging to younger generations today is associated with a greater extent of environmental concern. The results confirmed both the hypotheses, suggesting environmental policies that affect individuals in their everyday lives, such as recycling, besides being beneficial for the environment, and making the public opinion more conscious about the issue, also revealed that belonging to younger generations shows greater extents of environmental concern, perhaps due to the increased salience of the climate issue. To this regard, it would be interesting to delve deeper into this relationship, extending the scope of the research to other societies than just the Italian and Spanish one, using data that will be released in future waves to investigate whether 2018, with the FridayForFuture movement, really signaled a watershed event in the trends of environmental concern over different groups of society.

Moreover, the findings were overall consistent with the literature on the relationship between gender, higher income, and a higher level of education on the one hand and environmental concern on the other.

To conclude, social psychology has been applied for decades to marketing and economy, to the sole purpose of selling more and generating previously non-existent needs in the customer public. To a significant extent, it has been used to incentivize very unsustainable practices that have contributed and keep contributing daily to the environmental crisis we are facing now and still do not seem to know how to tackle. This research never had the arrogance to give a solution to this, as it is obvious. Its purpose was to show that the same psychological tools used to play cards against the environment could also play in its defense. Merely exposing human minds to a repeated stimulus does have an impact. It works for a pair of shoes we did not like the first time we saw them and eventually decided to buy - it also with a repeated sustainable behavior as it is that of meticulously dividing plastic from organic and paper from glass, even when we are not enthusiastic about doing it and we just do it to avoid being charged a fee from the local authority. Indeed, it is just one of the many strategies that could gain strength from those cognitive biases that make us take a decision rather than another without demanding a calculation of costs and benefits.

Alongside these strategies, it shall not be disregarded that some social groups need to be put in the position to care about the environment. High education shall neither be a privilege nor the path to temporal poverty; money shall not divide the society between those who believe the can and those who believe they cannot, and we shall stop raising men to the idea that caring is female and that female is bad. The path to sustainability does not look smooth, but it definitely needs to be walked before there is no ground at all to walk on.

\section{Bibliography}

Allen, R. S., Castano, E., \& Allen, P. D. (2007). “Conservatism and concern for the environment”, Quarterly Journal of Ideology, 30: $1-25$.

Babad, E., \& Katz, Y. (1991). "Wishful thinking—against all odds”, Journal of Applied Social Psychology, 21(23): 1921-1938.

Baldassarri, D. (2005). La semplice arte di votare. Le scorciatoie cognitive degli elettori italiani. Il Mulino.

Brechin, S. R., \& Kempton, W. (1994). "Global environmentalism: a challenge to the postmaterialism thesis?”, Social science quarterly, 75(2): 245-269.

Brough, A. R., Wilkie, J. E., Ma, J., Isaac, M. S., \& Gal, D. (2016). "Is eco-friendly unmanly? The green-feminine stereotype and its effect on sustainable consumption”, Journal of Consumer Research, 43(4): 567-582.

Delli Carpini, M., \& Keeter, S. (1991). "Stability and change in the U.S. public's knowledge of politics", Public Opinion Quarterly, 55: 583-612.

Deryugina, T. (2013). "How do people update? The effects of local weather fluctuations on beliefs about global warming", Climatic change, 118(2): 397-416.

Dimock, M. (2019). "Defining generations: Where Millennials end and Generation Z begins. Pew Research Center, 17: 1-7.

Dunlap, R. E., \& Heffernan, R. B. (1975). "Outdoor recreation and environmental concern: An empirical examination", Rural Sociology, 40(1): 18.

Dunlap, R. E., \& York, R. (2012). "The globalization of environmental concern”, Comparative Environmental Politics: Theory, Practice, and Prospects, 89-112.

Egan, P. J., \& Mullin, M. (2012). “Turning personal experience into political attitudes: The effect of local weather on Americans' perceptions about global warming”, The Journal of Politics, 74(3): 796-809.

Easton, D. (1957). "An approach to the analysis of political systems", World politics, 9(3): 383-400.

EVS (2020): European Values Study 2017: Integrated Dataset (EVS2017). GESIS Data Archive, Cologne. ZA7500 Data file Version 4.0.0, doi:10.4232/1.13560.

Feygina, I., Jost, J. T., \& Goldsmith, R. E. (2010). "System justification, the denial of global warming, and the possibility of "system-sanctioned change". Personality and social psychology bulletin, 36(3): 326-338. 
Fernandez, R., \& Rodrik, D. (1991). "Resistance to reform: Status quo bias in the presence of individual-specific uncertainty", The American economic review, 1146-1155.

Funk, C., Kennedy, B., Hefferon, M., \& Strauss, M. (2018). "Majorities see government efforts to protect the environment as insufficient”, Pew Research Center. Retrieved from www.pewresearch.org/science/wp-content/uploads/sites/16/2018/05/ PS_2018.05.14_energyclimate_FINAL.pdf on May 23, 2020.

Hartwig, M. G., \& Tkach-Kawasaki, L. (2020). "Correction to: Identifying the 'Fukushima Effect'in Germany through policy actors' responses: evidence from the G-GEPON 2 survey", Quality \& Quantity, 1-22.

Hatfield, J., \& Job, R. S. (2001). "Optimism bias about environmental degradation: The role of the range of impact of precautions", Journal of environmental Psychology, 21(1): 17-30.

INE. (2020). Estadisticas sobre recogida y tratamiento de residuos. Residuos urbanos: Serie 2010-2018. Retrieved from INEbase: https:/www.ine.es/jaxi/Datos.htm?path=/t26/e068/p01/serie/\&file=02003.px\#!tabs-tabla on April 8, 2020.

Inglehart, R. (1981). "Post-materialism in an environment of insecurity". The American Political Science Review, 880-900.

ISPRA. (2020). Catasto rifiuti sezione nazionale. Retrieved from ISPRA: https://www.catasto-rifiuti.isprambiente.it/index. php?pg=regione\&aa $=2019 \&$ regid $=$ on April 8, 2020

Jost, J. T., \& Andrews, R. (2011). "System justification theory”, The encyclopedia of peace psychology. London: Wiley-Blackwell.

Kahneman, D. (2011). Thinking, fast and slow. London: Penguin

Karlsson, N., Loewenstein, G., \& Seppi, D. (2009). "The ostrich effect: Selective attention to information", Journal of Risk and uncertainty, 38(2): 95-115.

Karp, L. (2005). "Global warming and hyperbolic discounting", Journal of Public Economics, 89(2-3): 261-282.

Kemmelmeier, M., Krol, G., \& Kim, Y. H. (2002). "Values, economics, and proenvironmental attitudes in 22 societies", Crosscultural research, 36(3): 256-285.

Kent, R. J., \& Allen, C. T. (1994). "Competitive interference effects in consumer memory for advertising: the role of brand familiarity", The Journal of Marketing, 58: 97-105.

Kilbourne, W. E., Beckmann, S. C., \& Thelen, E. (2002). "The role of the dominant social paradigm in environmental attitudes: A multinational examination", Journal of business Research, 55(3): 193-204.

Kitschelt, H. (1993). "The green phenomenon in Western party systems". En Kamieniecki, S. (ed.). Environmental politics in the international arena: Movements, parties, organizations and policy. Albany, NY: SUNY Press.

Kuligowski, E. D., \& Gwynne, S. M. (2010). "The need for behavioral theory in evacuation modeling", In Pedestrian and evacuation dynamics 2008. Berlin: Heidelberg, pp. 721-732

Kvaløy, B., Finseraas, H., \& Listhaug, O. (2012). "The publics' concern for global warming: A cross-national study of 47 countries", Journal of Peace Research, 49(1): 11-22.

Marshall, G. (2015). Don't even think about it: Why our brains are wired to ignore climate change. New York: Bloomsbury Publishing.

McCright, A. M. (2010). “The effects of gender on climate change knowledge and concern in the American public", Population and Environment, 32(1): 66-87.

Ministero dell'Ambiente. (2020). SIC, ZSC E ZPS IN ITALIA. Retrieved from Ministero dell'Ambiente: https://www.minambiente. it/pagina/sic-zsc-e-zps-italia on April 8, 2020.

MITECO. (2020). Red Natura 2000. Retrieved from MITECO: https://www.miteco.gob.es/es/biodiversidad/temas/espaciosprotegidos/red-natura-2000/ on April 8, 2020.

Monahan, J. L., Murphy, S. T., \&, Zajonc, R. B. (2000). "Subliminal mere exposure: Specific, general, and diffuse effects", Psychological Science, 11: 462-466.

Omer, H., \& Alon, N. (1994). "The continuity principle: A unified approach to disaster and trauma", American Journal of Community Psychology, 22(2): 273-287.

Puleo, A. H. (2013). Ecofeminismo para otro mundo posible. Madrid: Ediciones Cátedra.

Quoidbach, J., Gilbert, D. T., \& Wilson, T. D. (2013). “The end of history illusion”, Science, 339(6115): 96-98.

Richardson, D., \& Rootes, C. (2006). The green challenge: The development of green parties in Europe. London: Routledge.

Rodríguez, M. P., \& López, Y. H. (2010). "Ecofeminismo, una propuesta para repensar el presente y construir el futuro", CIPEcosocial. Boletín ECOS, 10: 1-3.

Sabbagh, C. (2005). "Environmentalism, right-wing extremism, and social justice beliefs among East German adolescents", International Journal of Psychology, 40(2):118-131.

Sniderman, P. M., Brody, R. A., \& Tetlock, P. E. (1991). Reasoning and Choice: Explorations in Political Psychology. New York, NY: Cambridge University Press.

Son Hing, L. S., Bobocel, D. R., Zanna, M. P., \& McBride, M. V. (2007). “Authoritarian dynamics and unethical decision making: High social dominance orientation leaders and high right-wing authoritarianism followers", Journal of personality and social psychology, 92(1): 67.

Taylor, P., Parker, K., Morin, R., Patten, E., \& Brown, A. (2014). Millennials in adulthood. Washington, DC: Pew Research Center.

Tversky, A., \& Kahneman, D. (1974). "Judgment under uncertainty: Heuristics and biases”, Science, 185(4157): $1124-1131$.

Valentine, P. V., \& Smith, T. E. (2002). "Finding something to do: The disaster continuity care model”, Brief Treatment \& Crisis Intervention, 2(2): 183.

Vázquez, P. Y. (2020). "Environmental concern in the global south: Tackling the post-materialist thesis and the impact of ideology". In Latin America in Times of Global Environmental Change. London: Cham, pp. 75-91

Watts, J. (2019). "The Greta Thunberg effect: at last, MPs focus on climate change”, The Guardian. Retrieved from https://www. theguardian.com/environment/2019/apr/23/greta-thunberg on April 8, 2020.

Zajonc, R. B. (1968). "The attitudinal effects of mere exposure", Journal of Personality and Social Psychology, 92: 1-27.

Zajonc, R. B. (2001). "Mere exposure: A gateway to the subliminal”, Current Directions in Psychological Science, 10: $224-228$. 